\title{
The significance of failure modes in the design and management of levees - a perspective from the International Levee Handbook team
}
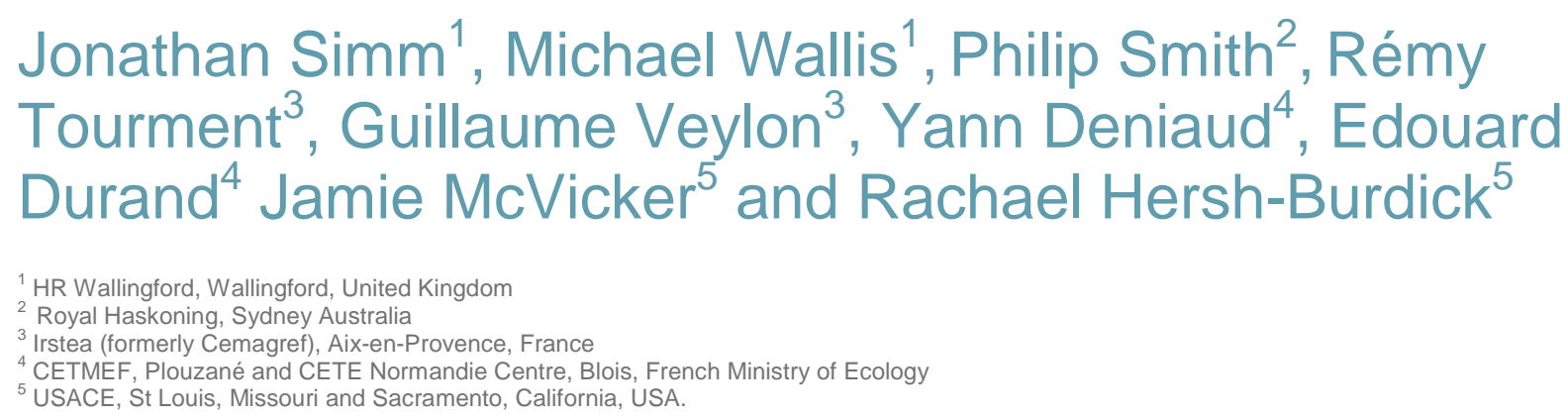

Published in the Proceedings of the 2nd European Conference on Flood Risk Management, FLOODrisk2012, Rotterdam, The Netherlands, 19-23 November 2012

\section{Abstract}

Deteriorating levees and recent well-publicised severe flood events have led to international concern about levee performance and failure. This has stimulated the production of the International Levee Handbook. A key starting point for the international authorship team was the acceptance that the issue of failure modes would pervade the entire handbook; a clear, concise and consistent classification and treatment of deterioration and damage mechanisms has therefore been developed with explanations of the ways these can link to generate breach scenarios. The ILH team has also established a relationship between levee form and function and the modes of failure that must be addressed to describe, design and manage a levee system. The team is currently developing methods for the analysis of these failure scenarios and their component mechanisms and the relation of these to the performance and reliability of the levee structure. When complete, the ILH will provide levee practitioners with a comprehensive and definitive guide which will facilitate sustainable design, construction and management practices.

\section{Introduction - the levee handbook}

\subsection{Definition of levees}

For the purpose of this paper, levees are defined as raised, predominantly earth, structures (sometimes called flood defence embankments or dikes) whose primary objective is to provide protection against fluvial and coastal flood events along coasts, rivers and artificial waterways (Figures 1,2) that are not reshaped under normal conditions by the action of waves and currents. 


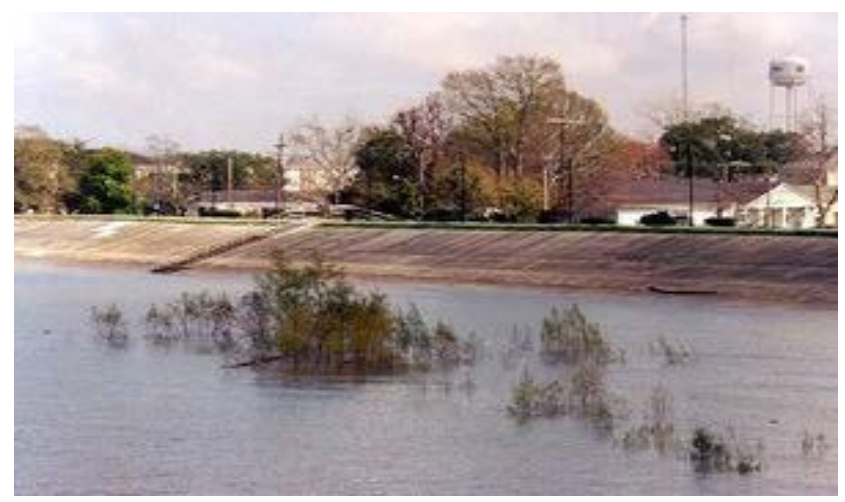

Figure 1: Typical river levee (along Mississippi River, USA)

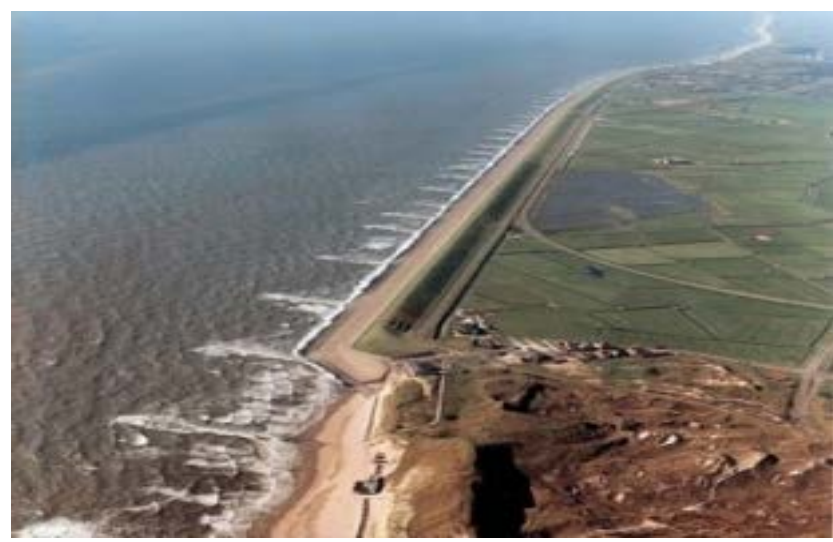

Figure 2: Typical coastal levee (The Netherlands)

Levees form part of flood defence systems that may also include flood walls, pumping stations, gate closure structures, natural features etc. Levees have been built up and extended over decades or sometimes centuries. Few were originally designed or constructed to modern standards and records of their construction and historical performance rarely exist.

Despite their apparent simplicity, levees can be complex structures. They have generally been constructed by placing locally won fill material onto alluvial flood plains (with all the inherent natural variability of such deposits). Unlike engineered structures built using concrete or steel, levees can be irregular in the standard and nature of their construction and can deteriorate markedly over time if not well maintained. Furthermore, levees are generally long linear structures which are part of an overall levee system; such systems should be considered as chains which are only as strong as the weakest link.

Evidence-based assessment, good design, effective adaptation, good inspection and maintenance are therefore vital if levees (particularly those representing the weakest parts of levee systems) are to perform well on the occasions when they are loaded in storm or flood events. It should be noted that levees may stand for much of their lives without being loaded to their design capacity. This can create a false sense of security in the level of protection they will provide.

\subsection{Motivation for handbook}

A number of serious flood events in recent years have brought to the international media's attention the role that levees (also known as flood defence embankments or dikes) play in managing flood risk, primarily because of the unprecedented loss of life and damage caused when such levees fail. Over the last decade major storms such as Hurricane Katrina in the US (2005), Tempête Xynthia in France (2010), torrential rain in Pakistan (2010) and torrential rain and snowmelt in the US (2011) have all resulted in serious flooding as a result of levees breaching or overtopping. As a result, billions of dollars are spent each year on levee construction, maintenance, repair and improvement (strengthening or raising). At the same time, climate change and socio-economic development continue to put extra strain on levee systems and indicate that it is no longer sustainable to take a piecemeal or single discipline approach to levee design, construction and management.

Concerns about these challenges and a desire to improve levee design and management has prompted organisations from six different countries (France, Germany, Ireland, the Netherlands, the UK and the USA) 
to come together to provide a guidance document - the International Levee Handbook (ILH) - for the management, design and construction of levees.(www.leveehandbook.net )

Production of the handbook is in progress. Technical work is expected to be completed by the March 2013 with publication by the London-based Construction Industry Research and Information Association (CIRIA) due later that year.

\section{Structure of the handbook}

The ILH will contain information that is useful for both existing and newly designed levees, however the structure of the handbook is such that existing levees are addressed first followed by newly designed levees. It is split into four main sections with a total of 10 chapters:

\subsection{Fundamentals}

Chapter 1 'Introduction' defines the structure, aims and scope of the handbook and explains how the document builds on and compliments existing manuals and guidance.

Chapter 2 'Conceptual frameworks' provides a generic management framework for flood defence systems which connects overlapping topics, bridges differences between countries, and puts levees in context with other parts of the flood defence system. It includes a flow diagram showing the framework for the life cycle management of a levee (Figure 3)

Chapter 3 'Form and function of levees' describes and illustrates the main types of levees and how they function with regard to flood risk. It discusses the influence of other structures associated with levees and the multi-functionality of levees. A section is also devoted to exampling the basics of failure modes for different types of levee.

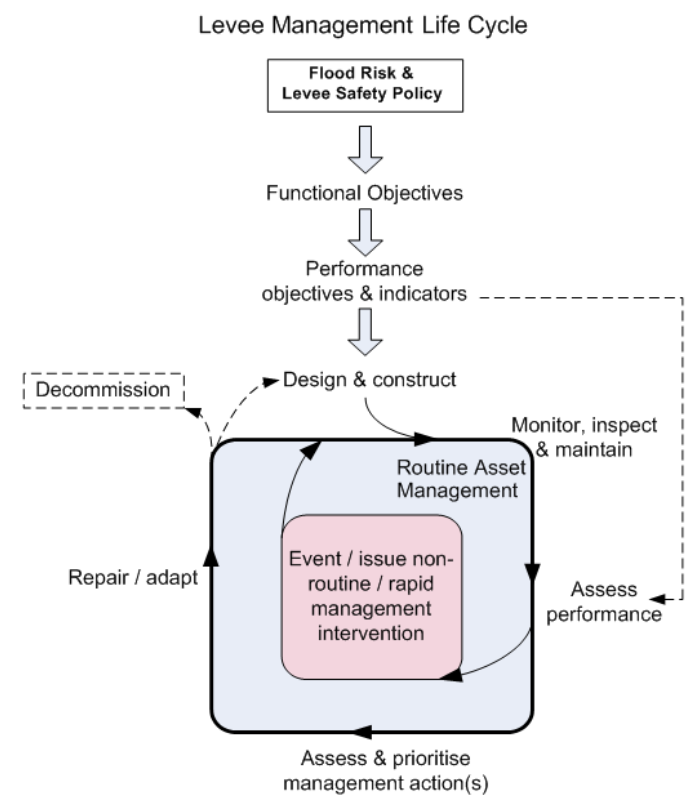

Figure 3: Levee management life cycle 


\subsection{Managing levees}

Chapter 4 'Operation and maintenance' addresses work that does not require detailed design. It discusses the role of maintenance in the face of deterioration and climate change including best practice and innovative methods. It highlights the competing goals of flood protection, the environment, and social well being.

Chapter 5 'Levee assessment and risk attribution' includes best practice procedures for diagnosis and condition assessment of levee structures in order to allow consistent and appropriate levels of reporting, including visual inspection, investigations and risk assessment. The chapter sets out a tiered approach to investigation of levee condition including inspection techniques and different types of investigations and provides recommendations for levee system risk assessment. The overall approach to monitoring is explained. Information systems to support levee management are discussed

Chapter $6 \quad$ 'Emergency preparedness and management' provides guidance on breach modelling with emphasis on the limitations and uses of the methods and preparing and implementing emergency action plans. It also includes guidance on event management, including methods for emergency breach repairs, post flood cleanup and data collection.

\subsection{Toolbox}

Chapter 7 'Site characterisation and data requirements' details site investigation methods and explains why these are critical for establishing appropriate boundary conditions and properties for design. It covers desk study procedures, intrusive and non-intrusive techniques for sampling and field investigation as well as relevant laboratory testing techniques and approaches to data interpretation that are suited to levees and the ground on which levees are built. This is followed by a section on recommendations for minimum or target levels of protection to provide flexible standards. It then establishes design loading criteria including environmental and social criteria for both coastal and fluvial levees. A section on the effects of climate change is also included in this chapter.

Chapter $8 \quad$ 'Physical processes and tools for levee design' demonstrates the need for a holistic approach to the design of levees that embraces both geotechnical and hydraulic engineering disciplines. It sets out the physical processes that control the performance of levees and indicates which analytical engineering methods and techniques best represent these characteristics. The chapter provides limit state equations for common damage and deterioration processes and discusses tools available for assessing breach and inundation. It provides examples of typical engineering calculations for both the assessment of existing structures and the design of completely new levees. The chapter also includes a summary of sophisticated geotechnical and hydraulic modelling techniques.

\subsection{Making changes}

Chapter 9 'Design' highlights the need for early specialist input from a variety of disciplines and a balance between engineering, environmental and social factors. Sections are included for design of remedial and improvement works, new levees, and removal of levees, including sections on planning and options appraisal. It provides recommendations on methods for taking levees out of service including realignment options. The chapter also highlights the potential impacts on adjacent sections (e.g. increased flood levels), and explains how to deal with these. Design manuals and codes are referenced where appropriate. This chapter also sets out the engineering principles and procedures that govern and characterise how levees 
perform. It demonstrates how these techniques can be used for design purposes and provides guidance and examples of best practice.

Chapter 10 'Construction' describes how construction practices and standards have changed over time. It includes implementing economic best practices, planning, designing for ease of construction, sourcing of suitable earthworks materials, practicing sustainable and innovative construction methods for decommissioning, maintenance, remediation, improvements, and new works. It highlights common problems and risks faced on different sites, including the need for a good knowledge of foundations, how soil variability can be addressed, dealing with a flood event during construction, programme constraints, environmental issues as well as the need for good quality control, monitoring and record keeping practices. A section is also included on availability and selection of materials, and one on plant and construction equipment, in particular for earthworks.

\section{Failure of levees - introduction}

The subject of levee performance and failure is clearly of great importance to the management of levee systems. The term 'failure' can be used inconsistently to describe many aspects of poor performance (for example, collapse during construction, shallow slippage, overtopping, seepage, erosion, piping or complete breach). In order to remove ambiguity and achieve a consistent approach to the description of the term 'failure', the authorship team decided to adopt three separate descriptive categories: deterioration (long-term process), damage (short term process given the deteriorated state of the levee) and breach. Deterioration encompasses those processes (settlement, desiccation, etc.) which change the state of the structure over a time-scale significantly greater than that of a single loading event. As the state of the levee deteriorates, the probability of damage (and consequential breaching) during a given flood event increases. Ultimate failure can be further sub-divided into two groupings; breach/collapse (structural failure) and functional (performance) failure such as overtopping occurring during a high water event greater than the design flood water level). The term 'overtopping failure' is used to describe overtopping at less than the design standard of the levee. Deterioration or damage, when coupled with a high water event can lead to overtopping and/or ultimately trigger a structural failure.

Fragility curves may be developed to model the impact of deterioration on performance. If the probability of damage due to a particular failure mode is represented by a fragility curve (probability of failure plotted against the applied hydraulic loads) then deterioration has the effect of changing the position and shape of this curve.

A large range of factors can affect the performance of a levee during a flood event and a failure will rarely be the result of just one factor. A combination of factors and events will usually be required to trigger a breach.. Thus, a potentially complex sequence of causes and consequences may need to connect or coincide for a breach to occur and often, this sequence starts with a deterioration process. An important point here is that the risk of failure can be significantly reduced by good maintenance. An example sequence of events that might eventually lead to a breach is presented in Figure 4. 


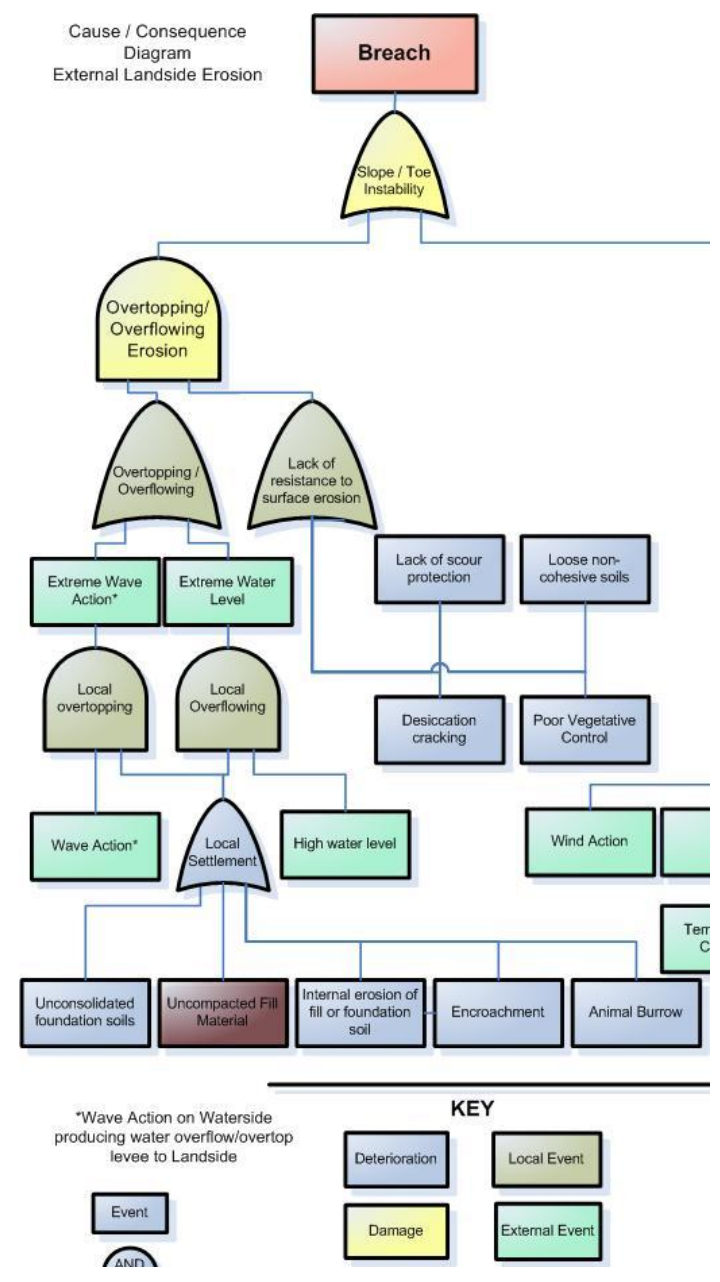

Figure 4: Part example of a levee cause-consequence diagram

\section{Dealing with levee failure in the Handbook}

\subsection{Systems approach}

A typical flood defence system consists of a chain of different structures, sometimes well thought out and designed, but sometimes haphazard as a result of historical development and adaptation. However, in every case, it is important to understand how the whole system works; if any one component of a flood defence system deteriorates, the risk of failure of that element increases and hence the performance of the whole system can be compromised.

In this situation, consideration must be given to the potential 'cascade effect' - the impact of the failure of one flood defence system on an adjacent system due to additional hydraulic loading. For example, flood defence systems are normally designed to resist wave or fluvial erosion on the waterside but can be comparatively fragile of the landward side. They can therefore be vulnerable to overflowing, overtopping or post-breach 
flows parallel to the levee. Clearly, the performance of a flood defence system during an event depends on the condition of its components at the time of flood as well as on the influence of the underlying ground conditions. In order for the system to perform during a flood event, each of these components must be adequately maintained on an on-going basis; it is impossible to improve long lengths of levee in a matter of days in the event of an adverse weather warning. However, history has taught us that when these extreme flood events occur only occasionally, levee maintenance tends to get postponed and delayed. As a result, these systems can be found wanting during times of emergency.

It should be noted that the transitions between different components are often the weak points in the system and, therefore, an area for careful design, construction and management. Without a secondary line of flood defence structures, any system is only as strong as its weakest link. This is a concern when there are multiple owners and different levels of flood risk mitigation, resulting in varying levels of engineering quality and/or management competence within a single flood risk management area.

It is important to be able to analyse and evaluate flood risk in order to be effective in mitigating against floods in an efficient and equitable manner. It is recognised that finance is limited and that there must therefore be a way of prioritising expenditure and resources on flood risk reduction measures. Flood risk analysis can be an important tool in this process of prioritising new works, repair and adaptation or for the planning of operations and maintenance programmes.

A flood risk management framework provides the organisational arrangements, policies and procedures that will embed flood risk management throughout a responsible organisation at all levels. As part of this framework, an organisation responsible for managing flood risks should have a policy or strategy for deciding when and how risks should be assessed and communicated.

A levee risk assessment is that part of risk management which provides a structured process that identifies how levee management objectives may be affected, and analyses the flood risk in terms of consequences and their probabilities before deciding on whether further treatment is required.

The risk that a levee may breach overflow or overtop at a given location is assessed by a risk analysis based on:

1. the nature of the area protected by the levee,

2. the consideration of the source of the initiating event (e.g. an extreme rainfall event, storm surge, etc.),

3. the performance or response of the levee when exposed to that event, and

4. the consequences incurred given that the flood occurs, reflecting the vulnerability of the receptors (e.g. people, property, environment, etc)

At a screening level, qualitative or semi-quantitative methods are used to make informed decisions for classification and prioritization. At a base condition risk assessment level, relatively simple quantitative methods are used to confirm levee safety issues and adjust portfolio priorities. At more demanding levels, increasingly sophisticated methods can be used to identify specific risk management options, recommend specific actions, and adjust portfolio priorities.

Risk attribution can be defined as the contribution of a specific component (e.g. a levee), (or group of components or levees in a flood defence system), to the level of flood risk incumbent on the receptors in the system. Attributing risk to each component of a system helps to target management interventions on those aspects which pose the greatest risks, in order to make cost-effective and environmentally-sound investment decisions. 


\subsection{Typology of levee failures}

A failure is defined as the inability to achieve a defined performance threshold (response given loading) (Allsop et al. 2007) or performance indicator. In the case of levees, failure occurs when a levee is no longer able to achieve, at the defined or assigned level of protection, its appropriate hydraulic function within the flood defence system. Failure is a state of a levee that results from a combination or a process of deterioration and damage.

Deterioration is a time dependant process that involves a decline in the state of the structural properties of the levee's components. Mechanisms of deterioration act on individual components of a particular section of levee and involve physical, chemical or natural processes such as settlement, desiccation, internal erosion, surface erosion and animal or human damage. These mechanisms cause damage which is manifested as cracks, fissures, locally low crest levels, voids, seepage, piping; these are observed as symptoms of deterioration. It is important to note that any one symptom can be attributed to a number of different mechanisms and any one failure mechanism can be initiated by deterioration of one or several components. Severe deterioration will result in damage of the structural components of the levee that require immediate repair or emergency action. Damage is generally triggered by external actions such as floods (causing hydraulic loading, external and internal erosion, seepage, etc.), post-flood rapid drawdown, unexpected applied loads, accidental loading or possibly seismic loading. In the long term deterioration and damage may eventually lead to breaching.

A structural failure of a levee section occurs when the weakness of one component of the levee reaches an incompatible ultimate state with its required threshold of structural performance (e.g. in relation to functions such as impermeability or stability), which can then in turn compromise the integrity of the whole levee.

Levees may also fail to perform without structural failure. Whilst a flood event simply exceeding the design event for a levee is not a performance failure, performance failure does arise if overtopping of a levee occurs at less than the design event. Such functional failures are related to changes in the surrounding conditions of the protection system, or incapacities in design, construction or management of the levees - mainly linked to human error.

The factors affecting a particular levee depend on its form, components, associated structures and the loading history. Scenarios or chains of events leading to a structural failure of a levee can be rather complex. Deterioration of a levee structure increases vulnerability and hence increases the risk of failure during a given event. Structural failures may require a combination of mechanisms to occur and these can be causal or independent.

Transition zones are interfaces between different components or between a levee and an adjacent or embedded structure. As transition zones are characterized by major discontinuity in properties of materials, they are weak points of a levee structure and a high risk area. Transition zones locate the deformations and the failure processes. They historically provide a focal point for flow concentration or turbulence which results in scouring and erosion of the levee. They are locations that are frequently associated with the development of mechanisms of deterioration and of damage. Embedded structures within the levee, such as utility or pipe lines can also trigger such erosion.

In the Levee Handbook, individual mechanisms of deterioration and of damage that affect a levee, have been grouped into main generic types, or modes, that are described below: 


\subsubsection{External erosion}

External erosion is the wearing away of a surface (bank, streambed, embankment, or other surface) by floods, waves, wind, or any other natural process. (FEMA 2004). External erosion is initiated by hydrodynamic forces acting on soil particles at the surface of a levee. It occurs when the surface material of the levee is not sufficiently resistant to the aggressions of the environment, that is, when the shear stress induced by flows, exceeds the critical value associated with the nature of the materials of the levee.

External erosion of a waterside face of a levee is mainly caused by the action of waves, currents or turbulence within the channel. On the landward side of a levee, overtopping, overflowing or post-flood laminar flow can induce major damage like scour holes and erosional features.

\subsubsection{Internal erosion}

Internal erosion is initiated by hydrodynamic forces acting on soil particles inside or through the body of a levee. Internal erosion occurs when soil particles within a levee or its foundation, are carried downstream by seepage flow (CIGB-ICOLD 2012). In this process, the migration of material particles, induced by pore pressure and flow of interstitial water, can eventually form channels through the levee embankment, within the foundation soils, along penetrating structures or at the boundary between the soil and appurtenant structures (see Figure 5). These pipes undermine the structure of the levee and lead to a failure and a breach when the seepage is uncontrolled and a steady passage of water through, underneath or around a levee occurs. Various types of mechanisms of internal erosion were categorized (CIGB-ICOLD 2012), such as: backward erosion, concentrated erosion, contact erosion, and suffusion.

\subsubsection{Mass instability}

Mass instability occurs when the sum of the disturbing actions (self weight, applied loads, etc.) applied on a potential failure surface exceed the sum of the resistances (strengths) of the materials along that failure surface. For hydraulic structures such as levees, the hydraulic loading can have a significant impact on the magnitude of both the applied actions and the mobilisation resistances. In levees, failure mechanisms such as rotational or translational sliding are commonly identified as being critical to the design and these can often be influenced by hydraulic or piezometric phenomena such as seepage, uplift and liquefaction.

\subsubsection{Deterioration vs damage example}

The relationship between deterioration and damage can be illustrated by the example of a levee subject to internal erosion in the levee core, in its foundation soils or along a penetrating structure (see Figure 5).

Deterioration starts when the velocity flow of seepage is sufficient to initiate the movement of particles of soil relative to one another (this is the initiation stage of the mechanism of backward erosion). If the transportation of mobile particles is not inhibited by a filter layer, the erosion will continue and accelerate as the permeability of the layer increases (continuation stage). 


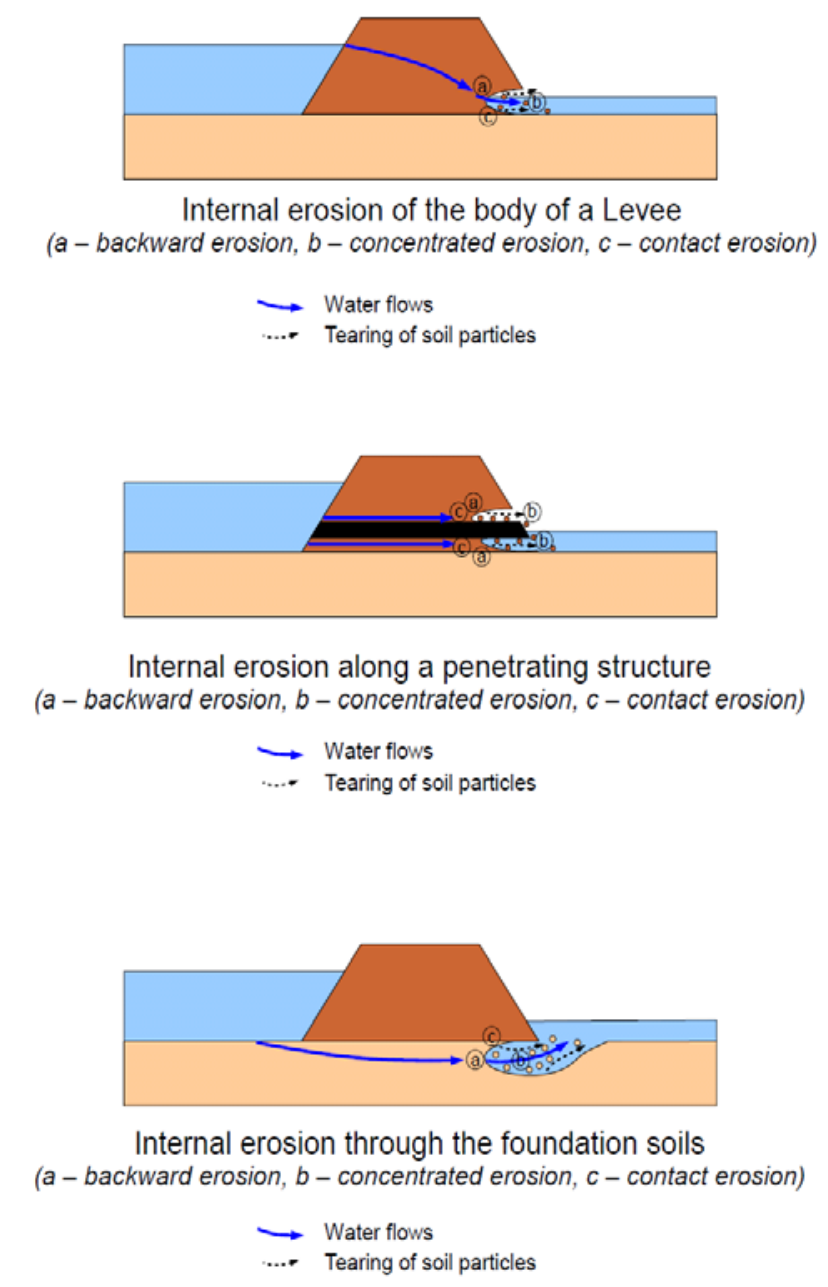

Figure 5: Forms of internal erosion mechanism

The consequences of internal erosion are the creation of voids and the increase of both pore pressures in and seepage through the downstream part of the levee or its foundation. Eventually, the internal erosion can form and sustain a pipe (progression stage - mechanism of concentrated erosion and possible mechanism of contact erosion). These processes are gradual; the rate at which they take place depends on both the characteristics of the materials present and the environmental conditions. They are processes of deterioration.

At some point, major damage such as a complete pipe that allows the free passage of water through or beneath the levee failure may occur. This may trigger a collapse of the crest that allows water to overflow the levee (breach stage - mechanism of piping and collapse). This damage can be triggered by an external event like a high water level occurring after the collapse of the pipe. Generally, the speed of these processes increases dramatically as collapse approaches; by the time that an imminent failure is apparent, there may be insufficient time to carry out an urgent repair. 


\subsection{Deterioration and damage: identification and management actions}

The process of deterioration generally takes place over an extended period of time. As it progresses, the probability of levee failure during a given event increases. This progression needs to be overcome and hence the focus of Chapter 4 of the ILH is to provide the operator and maintainer of the levee with enough information to understand the basic principles behind these deterioration processes so that they can effectively maintain the levee without the help of a professional designer. The deterioration processes discussed in Chapter 4 include the following:

- Desiccation or settlement cracks in the levee can weaken the levee in two primary ways: they allow water to enter the levee through the crack leading to saturation and reduced soil strength. They can also trigger slope instability through the loss of soil resistance along the failure surface.

- Animal burrows threaten the levee by: providing a direct path for through seepage - dramatically increasing the threat from internal erosion and by creating voids in the levee leading to a collapse of the levee crest.

- Seepage is a concern if it causes the levee toe to become saturated, or if it causes internal erosion (and eventually piping).

Preventative measures that a maintainer can take to prevent these issues from occurring are presented in Chapter 4 along with repairs that the maintainer can make if the problem does occur. Rules of thumb are included to help the maintainer know when the issue has progressed to the point that the services of a professional designer are required.

Other concerns include how to prevent and repair defects related to structures which interface with the levee. These transition points at interfaces with levees tend to be points of weakness. A few of the key structures discussed are:

- Culverts and discharge pipes which can leak and cause saturation of the levee; collapse and cause damage to the levee crest; carry substances which may leak and damage the levee through softening or internal erosion or causing environmental damage to the local area.

- Floodwalls can have numerous issues including: deteriorating joints which can lead to spalling, cracking or loss of water tightness; or inadequate scour protection to resist wave action leading to deterioration of the floodwall and a point of weakness at the transition between the floodwall and the earthen levee. Any issue with the floodwall can create an unanticipated path for water to flow through the flood defence and increase the risk of overflowing or external erosion depending on the position of the floodwall.

- Closure structures which if inoperable, leave a gap in the system allowing water to penetrate the line of protection below the design water stage. This can increase external erosion to the levee.

\subsection{Levee assessment for failures}

Chapter 5 of the ILH deals with risk analysis and performance assessment of levees and flood defence systems, including data gathering for these analytic activities.

The assessment processes described relate to the potential failure modes of a given levee. For each of these modes, the objective is to produce an assessment of the potential for failure or breach. Risk analyses based on levee assessments include the consequences of a failure or a breach in the system. The data gathering activities include visual inspections, investigations, instrumentation and monitoring. Assessment 
methods can use different data combining processes, ranging from rapid expert judgement, calculations based on physical or empirical models (detailed in Chapter 8), index based methods, and finally complex expert analysis combining all of these approaches.

One objective of a levee assessment is to determine (by way of a consideration of the condition of its components) possible breaching scenarios involving different chains of physical mechanisms. If all the relevant data related to a breaching scenario can be gathered and combined, then some mechanisms, like mass instability, can be analysed by way of equations which approximate to the real physical process.

Good data is vital for the analysis of the elementary mechanisms of a failure scenario. Such data may relate to an initiating factor, or to terms of a mathematical relationship quantifying it, or to indicators of the mechanism actually occurring. For instance, in the case of mass instability, field data can be used to estimate physical parameters (c, phi, density) for use in the mathematical models of the physical phenomenon. In some cases, however, like suffusion, reliance has to be placed on indirectly related physical parameters or indicators from visual inspection.

For internal erosion analysis, it is also necessary to make the distinction between the different elementary mechanisms: suffusion, backwards internal erosion, contact erosion and concentrated leak erosion.(see also 4.5 below) A proper understanding of these elementary mechanisms can help in analysis. For example:

n watertightness is important, so permeability is an indirect parameter, as is also granulometry (the combination of soil grading and angularity);

- resistance to suffusion is also influenced by granulometry, as well as the detail of the interfaces between filters;

- concentrated leak erosion can be calculated, but in the case of an internal erosion mechanism chain, this is just the final, not the initiating, mechanism.

\subsection{Emergency management}

Chapter 6 discusses emergency management setting the management of levees in flood events in the context of wider emergency operations. The management of incipient failures is discussed, including for example, managing sand boils in such a way as to control internal erosion processes.

\subsection{Analysis tools for levee failures}

Chapter 7 of the ILH describes the detailed methodologies and techniques for determining hydraulic characteristics for a site, topographic and ground models and geotechnical parameters. These factors can then be used for analysis or design using the analytical tools set out in Chapter 8 . These calculation procedures can be applied to issues of stability and collapse but they can also be applied to the processes of deterioration (settlement, suffusion, etc).

Each of these individual mechanisms is treated from the simplest to the more complex. The experimental and theoretical bases of the analytical methods are briefly described and the advantages and disadvantages of each method are discussed in terms of conditions of use and accuracy of the results. The different approaches are expressed increasing in complexity, through rules of thumb empirical formulae, and analytical models or numerical methods. 
The section on internal erosion for example, focuses on the four mechanisms identified in the CIGB-ICOLD glossary (CIGB-ICOLD, 2012):

- Backward erosion: critical gradient evaluation models by Bligh (1910) and Sellmeijer (2011).

- Suffusion: granulometric criteria for soil stability from Kezdi (1979), Kenney \& Lau (1985), and Li \& Fannin (2008).

- Contact erosion: critical flow velocity determination from granulometric data (Brauns, 1985).

- Concentrated leak erosion: shear stress erosion law calibrated from hole erosion tests (Bonelli, 2008).

Numerical modelling of the internal erosion mechanisms and the limitations of each approach are discussed. Finally, an example of analysis is given to make the presentation more concrete and practical.

The end of Chapter 8 is devoted to breach modelling and inundation mapping issues. It describes the basic assumptions of the models and provides a toolbox for the selection of an accurate hydraulic model, considering the uncertainty level on the input data and the precision objectives of the analysis.

\subsection{Design approach and details}

The outcome of a flood study or a condition assessment may be that change to the existing regime is required. In this case, a new levee, or adaptations to an existing of levee will need to be designed. The design process pulls together many of the above components in order to create an effective structure that can be built. It goes without saying that the designer or the design team should have sufficient knowledge of all aspects of levee behaviour (including an understanding of all of the potential failure mechanisms) to be able to complete the design.

The design process can be applied to the construction of new levees, to the adaptation of existing levees (such as levee raising), to substantial repairs or to decommissioning. However, the level of detail will clearly depend on the nature of the project.

The design process is normally broken down into stages: preliminary design (including environmental impact assessment, option selection, planning and public consultation) and then, once the final option has been selected, detailed design which includes the production of drawings and specifications for use in construction.

To produce an appropriate and cost-effective design, the designer must understand the owner/operator's constraints and objectives and assimilate the relevant available information about both the levee and the site. This data may include:

v the construction and performance history of any existing levee at the site (in so far as this information is available);

- the hydraulic characteristics of the site and the levee (e.g. tidal range, wave and current loads, flood water levels corresponding to the design return periods, etc.);

- the nature and characteristics of the ground and any existing levees at the site. This is done by a staged process of condition assessment, desk study and ground investigation to whatever degree is appropriate. This will normally result in the compilation of a ground model and the determination of geotechnical design parameters.

The above information should be compiled into a 'Basis of Design' report before any design calculations are undertaken. This gives the designer and the owner / operator a chance to agree on the final objectives before significant design calculations are carried out. 
The design process then follows through a number of logical steps (which may not all be required in every situation):

- Finalise the design objectives and establish the boundary conditions.

- Determine the geometrical levee alignment on plan (e.g. close to the river or set-back).

- Establish minimum operational topographic requirements so as to define the minimum cross sections

- Check geotechnical stability of the levee for all relevant failure mechanisms (e.g. end of construction, design flood levels and piezometric conditions for shallow slips, deep rotational failures, translational failures, uplift, etc., the stability of crest structures such as embedded or gravity walls, post-flood rapid drawdown, etc.).

- The designer must then consider serviceability requirements such as settlement over the design life of the structure, levee permeability, the stability of material interfaces within the levee to internal erosion. This may require that a cut-off is incorporated into the levee to inhibit the passage of water and to control both hydraulic gradients and flow velocities or the installation of pressure relief drains. The designer should reconsider the issue of stability after making such changes to check that neither the cut-off structure nor the levee are adversely affected by the incorporation of the cut-off structure.

- Finally, consideration should be given to the issue of resilience of the levee to accidental loading or extreme conditions (for example, how will the levee perform if the water level exceeds the design requirements and overtops as a result?).

In producing the design, the designer must consider constructability issues such as the location of the soil used for levee construction, safe working access for the constructor to get to the site and then work at the site. The designer should liaise with experienced levee constructors on such issues.

The output from the design process usually consists of the blueprints for construction (the drawings and technical specifications). The ILH authors also recommend that a design report and an operations and maintenance manual are produced as part of the design and then handed to the owner / operator on completion of levee construction.

Designers of levees face conflicting requirements as a result of financial, environmental, safety and risk pressures. They can be responsible for designing hundreds of kilometres of levee. A risk based approach is therefore often used to prioritise levee design. In this situation, it is imperative that all parties (asset owners / operators, designers and the affected general public) are aware of the standards of protection adopted for each levee section and of the consequences of a flood event exceeding the conditions for which the levee has been designed.

A common dilemma facing levee designers is the selection of suitable fill material for levee construction. Levees can be located great distances from the location of ideal construction materials. In this situation, it is often better to use local material that may not be ideal for levee construction rather than to import preferred materials over great distances (at considerable cost and potential impact on the local environment). In this case, the designer has to find a working solution that may entail:

- adapting the geometry of the levee by designing a levee with flat side slopes to avoid problems of instability, or a wide crest to decrease permeability;

- incorporating cut-offs or other structures to inhibit the flow of water through the levee in the case of a flood;

- carrying out special design calculations such as transient seepage calculations rather than simpler steady state calculations to assess how a levee will react to the duration and magnitude of a given flood event; and 
- considering the details of all material interfaces so that they are designed to be stable against suffusion during the design flood event.

\section{Conclusions}

The International Levee Handbook will provide a benchmark guidance document for the management and operation of existing levees and the design and construction of new levees or remedial works. The anticipated readership therefore includes levee owners, managers, designers, constructors, risk analysts, regulatory authorities and others.

The central theme of the handbook is an appropriate understanding of deterioration and damage mechanisms for levees. This paper has explained how these various mechanisms are characterised and may combine in failure scenarios, ultimately leading to breach. The paper goes on to explain the kinds of approaches discussed in the Handbook to address these mechanisms in the various stages of levee operation, management, design and construction

\section{References}

Allsop, W., Kortenhaus, A. \& Morris, M., 2007. FLOODsite - Failure Mechanisms for Flood Defence Structures, FLOODsite. Available at: http://www.floodsite.net/html/partner_area/project_docs/ T04_06_01_failure_mechanisms_D4_1_v1_1_p01.pdf.

Bligh, W. G., 1910, Dams barrages and weirs on porous foundations, Engineering News, p. 708.

Bonelli, S. \& Brivois, O., 2008, The scaling law in the hole erosion test with a constant pressure drop, International Journal for Numerical and Analytical Methods in Geomechanics, Vol.32, pp1573-1595.

CIGB-ICOLD, 2012. Internal erosion of existing dams, levees, and dikes, and their foundations - International Glossary. CIGB-ICOLD Bulletin, (1), p.2-8.

FEMA, 2004. Federal Guidelines for Dam Safety - Glossary of Terms. Available at: http://www.ferc.gov/industries/hydropower/safety/guidelines/fema-148.pdf.

Kenney, T. C. \& Lau, D., 1985, Internal stability of granular filters, Canadian Geotechnical Journal, Vol.22, pp215-225.

Kezdi A (1979), Soil physics - selected topics, Elsevier Scientific Publishing Co., Amsterdam, 160 pp.

Li, M. \& Fannin, N. R. J., 2008, A comparison of two criteria for internal stability of granular soils, Canadian Geotechnical Journal, Vol.45, pp.1303-1309.

Sellmeijer, J. B., Lopez de la Cruz, J., Van Beek, V. M. \& Knoeff, H., 2011, Fine-tuning of the backward erosion piping model through small-scale, medium-scale and IJkdijk experiments, European Journal of Environmental and Civil Engineering, Vol.15 (8), pp1139-1154. 